\title{
Evaluation and modifying of The Al-khateeb model for estimation of the dynamic modulus of Western Australian asphalt mixtures containing recycled asphalt pavement
}

\author{
Hassan Malekzehtab, Hamid Nikraz
}

\begin{abstract}
In this study, a well-known dynamic modulus prediction method, the Al-khateeb model, is evaluated to see how it performs to estimate dynamic modulus of asphalt mixtures designed and made based on Western Australian asphalt specifications and materials. The parameters needed for this model are obtained through laboratory tests on binder and mixture properties. Also, the actual dynamic modulus of asphalt samples is obtained through testing the samples which are made with the same mixtures and tested in Asphalt Mixture Performance Tester (AMPT) machine in a series of different loading frequencies and temperatures. Later the results of the model are compared with the actual results. The results showed that even though this model is very common in literature, it does not perform satisfactorily for mixtures in this study. Therefore, some modifications were made on the model to improve its accuracy.
\end{abstract}

Keywords-Dynamic Modulus, Prediction Model, Al-khateeb model, Mixtures Parallel Model, Western Australian asphalt mixtures, Recycled Asphalt Material

\section{Introduction}

The dynamic modulus $\left(\mathrm{E}^{*}\right)$ of the asphalt mixtures is an imperative parameter in many asphalt pavement design standards. [1,2]. This parameter is affected by both elastic and viscous behaviour of the asphalt sample under harmonic loads. This test can be done in various load frequencies and temperatures to determine the response of the asphalt mixture in different conditions. It can be also done in compression mode, tension mode and the combination of both modes, while the results are not expected to be different as it is suggested by [3] that asphalt concrete is an isotropic material. There are several methods to perform this test. For example, it is suggested by [4] to utilise indirect tensile test to measure the dynamic modulus of the samples. However, the typical approach is to measure the response of the compacted cylindrical sample under a sinusoidal loading as [5] and [6] suggested.

However, performing the tests to measure the dynamic

Hassan Malekzehtab

PhD Candidate, Curtin University

Australia

Professore Hamid Nikraz

Curtin University

Australia modulus of an asphalt mixture, is a costly and time-consuming procedure. Also, this parameter, in some standards, might be needed in the design phase of a project. Therefore, developing a method to accurately predict this parameter is very important.

\section{Literature Review}

Many studies have been done to achieve a prediction model which can perform satisfactorily. Some of these models are Witczak 1-37A, Witczak 1-40D, Hirsch model, Al-khateeb model (also known as mixtures parallel model) as well as artificial intelligence based methods including the artificial neural network. [7], [8], [9] [10]. However, none of these models include the asphalt mixtures designed by Western Australian (WA) materials and standards. This might cause a significant error as materials and specifications in WA are different in some aspects from other places. Also, some of these models have not considered the possibility of RAP inclusion in the mixture and its effects on the mixtures' response. Therefore it is not clear whether these methods can be applied to the mixtures in the WA which might contain recycled asphalt pavement. In this study, the Al-khateeb model is selected to be evaluated for the RAP contained WA mixtures as this model requires the least parameters in comparison to other models and also because of its simplicity to use. In this study, the Al-khateeb model is evaluated and then its performance is improved by calibrating its parameters according to the data available in this research.

\section{Methodology}

To assess the accuracy of the results of the Al-khateeb model for the WA's asphalt mixtures a variety of samples with different nominal aggregates size and RAP content were made and then tested under different loading frequencies and temperatures. In this study, 150 data points in total were collected for dynamic modulus of asphalt mixtures. Then the results were compared with the dynamic modulus estimated by the Al-khateeb model based on the properties of each sample. Later, the parameters of the model were adjusted to improve its accuracy. The details of each of these steps are described in the following subsections.

\section{A. Al-khateeb model for $E^{*}$ prediction of asphalt mixtures}

In this model, a composite three-phase system (including aggregates, asphalt binder, and air voids) was utilised to develop the relationship between the properties of the mixture and its dynamic modulus [8]. Based on the experiments done by Al-khateeb, this relationship is as shown in (1). 
Proc. of the Fourth International Conference on Advances in Civil, Structural and Environmental Engineering - ACSEE 2016. Copyright ( $\odot$ Institute of Research Engineers and Doctors. All rights reserved.

ISBN: 978-1-63248-114-6 doi: 10.15224/ 978-1-63248-114-6-30

$$
\left|E^{*}\right|_{m}=3\left(\frac{100-V M A}{100}\right)\left(\frac{\left(90+10000 \frac{\left.G^{*}\right|_{b}}{V M A}\right)^{0.66}}{1100+\left(900 \frac{\left|G^{*}\right|_{b}}{V M A}\right)^{0.66}}\right)\left|G^{*}\right|_{g}
$$

where, $\left|E^{*}\right| m$ is dynamic modulus of HMA (psi), $\left|G^{*}\right| b$ is dynamic shear modulus of binder ( $\mathrm{psi}$ ), VMA is percentage of voids in mineral aggregates and $\left|\mathrm{G}^{*}\right| \mathrm{g}$ is glassy modulus of binder (psi): $\left|\mathrm{G}^{*}\right| \mathrm{g}$ is usually taken as being equal to 145000 psi.

\section{B. Experimental program}

\section{1) Materials and mixtures}

In this study, two typical asphalt mixtures with 14 and $20 \mathrm{~mm}$ nominal aggregates sizes were designed using the C 320 binder. The $14 \mathrm{~mm}$ mixture is redesigned to incorporate 4 different levels of RAP; $0,10,20$ and $30 \%$ by the total weight of the mixture. To ensure the results can be applied to the WA's mixtures, the material and binders were all collected from an asphalt plant and the mixture design was based on WA Mainroad's specifications and approved job mix design from the asphalt plant. The particle size distributions of the 14 and $20 \mathrm{~mm}$ mixtures are shown in Fig.1 and Fig.2 respectively. Also, the binder contents of the mixtures are 4.7 and $4.3 \%$ by the total weight for 14 and $20 \mathrm{~mm}$ mixtures respectively.

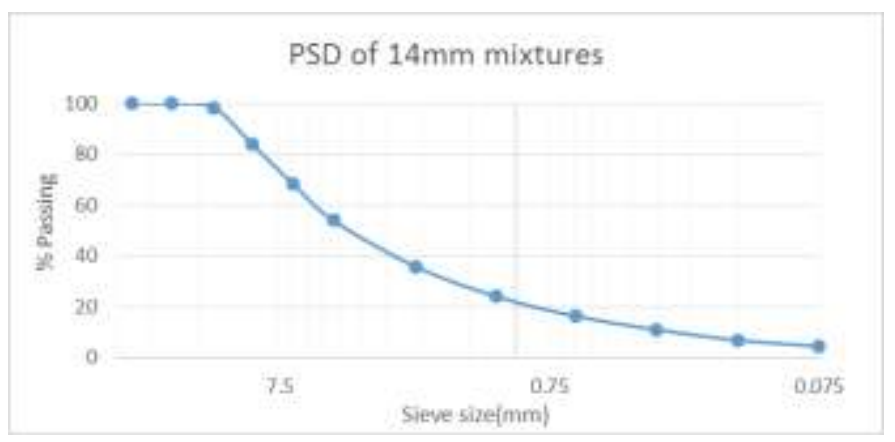

Figure 1. Particle size distribution of $14 \mathrm{~mm}$ mixtures

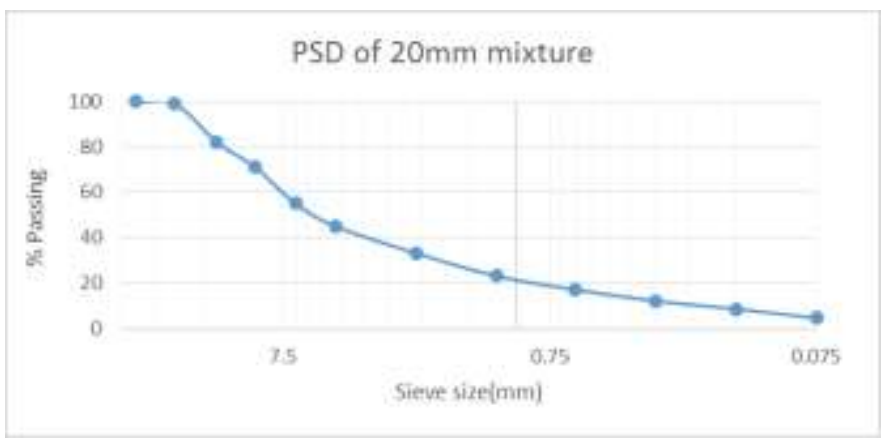

Figure 2. Particle size distribution of $14 \mathrm{~mm}$ mixtures

By testing the binder content and PSD of the RAP, the amount of virgin binder and aggregates of $14 \mathrm{~mm}$ mixtures were redesigned to incorporate $0,10,20$ and $30 \%$ of RAP with the same final PSD and binder content, assuming the binder in the RAP was totally blended in the mixture.

\section{2) Sample preparation and dynamic modulus testing}

In this research, at least three samples were made for each mixture. These samples were made by pouring hot asphalt mixture into a cylindrical mould and then compacting using gyratory compactor. Then the cylindrical samples $(150 \mathrm{~mm}$ height, $100 \mathrm{~mm}$ diameter) were taken from the compacted material by coring and cutting the compacted sample. The air voids and voids in the mineral aggregates of the samples were then measured according to WA Main roads specification [11]. Having the sample ready for test in AMPT machine from IPC Global Company, sinusoidal compression was applied on each sample at different temperatures while monitoring the response of the sample. The frequencies and temperatures utilized in this study are shown in Table I. TABLE I. LOAD FREQUENCIES AT EACH TEST TEMPERATURE FOR
ASPHALT SAMPLES DYNAMIC MODULUS TEST

\begin{tabular}{|c|c|}
\hline Temperatures $\left({ }^{\circ} \mathrm{C}\right)$ & Frequencies $(\mathrm{Hz})$ \\
\hline 4 & $10.0,1.0,0.1,0.01$ \\
\hline 20 and 40 & $10.0,1.0,0.1$ \\
\hline
\end{tabular}

By processing the load and the response of the sample over time as schematically shown in Fig. 3the dynamic modulus of the sample can be calculated using (2).

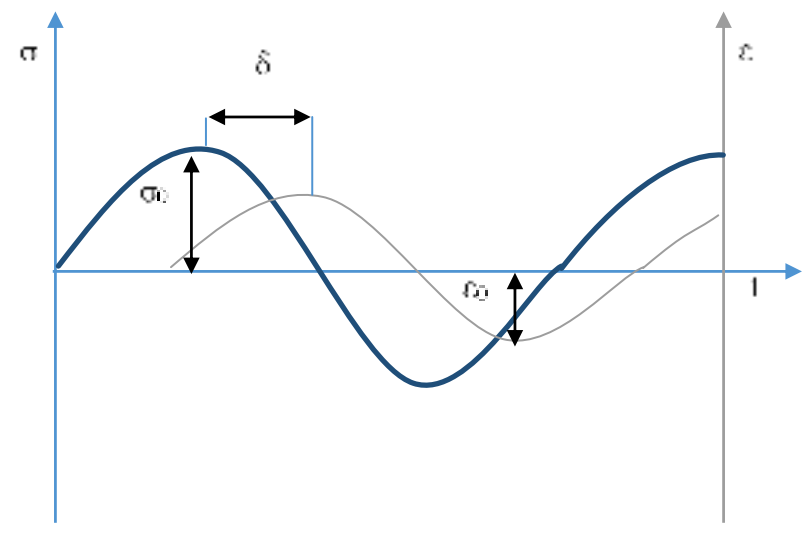

Figure 3. Schematic graph of applied stress and monitored strain over time in dynamic modulus test

$$
\left|E^{*}\right|=\frac{\sigma_{0}}{\epsilon_{\mathrm{n}}}
$$

where, $\sigma$ is an applied stress, $\varepsilon$ is a measured strain, $\sigma_{0}$ is the amplitude of applied stress, $\varepsilon_{0}$ is the amplitude of measure strain, $\mathrm{t}$ is time and $\delta$ is the phase angle. For completely elastic materials, $\delta$ is $0^{\circ}$ while for completely viscous it is equal to $90^{\circ}$ [12]. Considering all the samples in different conditions, totally, 150 data points were collected and used in this study. 
Proc. of the Fourth International Conference on Advances in Civil, Structural and Environmental Engineering - ACSEE 2016. Copyright $(\odot$ Institute of Research Engineers and Doctors. All rights reserved. ISBN: 978-1-63248-114-6 doi: 10.15224/ 978-1-63248-114-6-30

\section{3) Binder properties}

As it was explained in section A, the Al-khateeb model requires the dynamic shear modulus of the binders in the mixture. To provide this parameter when designing a new mix, the provided properties of the binder from its supplier or the result of a blending chart (when a combination of binders are in the mixture) can be used. However, in this study, to eliminate error in the estimation of the binder properties, the binders of each mixture were recovered using a solvent and rotary evaporator according to [13] and [14]. The recovered binders then were tested in $5,20,30$ and $40^{\circ} \mathrm{C}$ in a dynamic shear rheometer (DSR) machine at frequencies between 0.1 to $10 \mathrm{~Hz}$. To ensure the results were consistent, the binder recovery was done two times per mixture and two samples from each recovery of a mixture were tested in the DSR machine. It should be noted that in some cases, no DSR data was available for exactly the conditions that the asphalt mixtures were tested. For instance, no binder tested at $4^{\circ} \mathrm{C}$. Also, at $40^{\circ} \mathrm{C}$, there is no binder data available for $0.01 \mathrm{~Hz}$. In these cases, the concept of time-temperature superposition principle was utilised to find the response of the binder in temperature or frequencies other than what were measured in a similar procedure recommended in [6]. A shift factor function can shift the frequency of a record data to its equivalent frequency at reference temperature as (3) shows.

$$
a_{T}=\frac{\omega_{r}}{\omega}
$$

where, $\omega_{\mathrm{r}}$ is the reduced frequency at the reference temperature, $\omega$ is the frequency of the data from the experiment and $\mathrm{a}_{\mathrm{T}}$ is the shift factor at a temperature of interest T. In this study, Arrhenius function as illustrated in (4) considered as a shift factor function.

$$
\log a_{T}=C\left(\frac{1}{T}-\frac{1}{T_{r e f}}\right)
$$

Where $\mathrm{T}$ is the actual temperature $\left({ }^{\circ} \mathrm{K}\right)$, Tref is a reference temperature $\left({ }^{\circ} \mathrm{K}\right)$ and $\mathrm{C}$ is an adjustment constant. An equation of a master curve of a binder, curve which consists of shifted data of a binder at a reference temperature, can be assumed to be a sigmoidal [15] as (5) illustrates.

$$
\log \left|E^{*}\right|=\delta+\frac{\alpha}{1+e^{\beta+\gamma\left(\log \omega_{r}\right)}}
$$

where, $\mathrm{E}^{*}$ is the complex modulus of a binder, $\omega_{\mathrm{r}}$ is the reduced frequency $(\mathrm{Hz}), \delta$ is the minimum value of $\left|\mathrm{E}^{*}\right|, \alpha$ is the difference between the maximum and minimum value of $\left|\mathrm{E}^{*}\right|$ while $\beta$ and $\gamma$ are adjustable constants. The maximum value of $E^{*}$ can be assumed to be the glossy modulus which is can be considered to be $1 \mathrm{GPa}$ (145000psi). [6].

Finally to construct the master curve of a binder at the reference temperature, the adjustable constants in shift factor and sigmoidal function were optimized to fit the master curve to the shifted data available from the experiments. This optimization was done using the Solver toolbox of Microsoft Excel. The master curve of binders at 4 and $40^{\circ} \mathrm{C}$ are shown in Fig. 4 and Fig. 5 respectively.

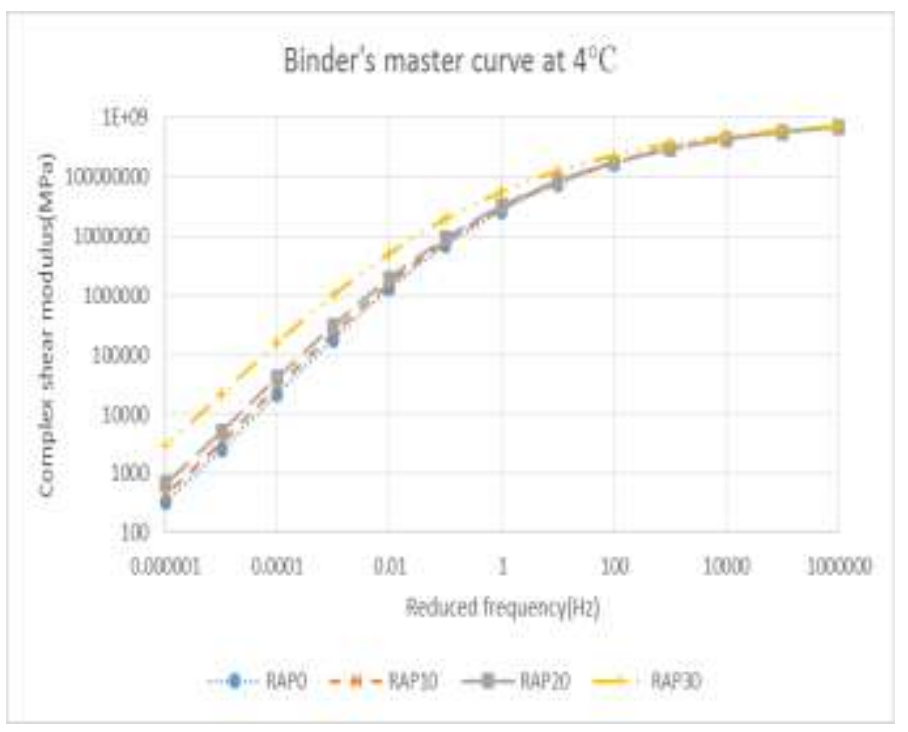

Figure 4. Master curve of binders recovered from mixtures at $4^{\circ} \mathrm{C}$ reference temperature

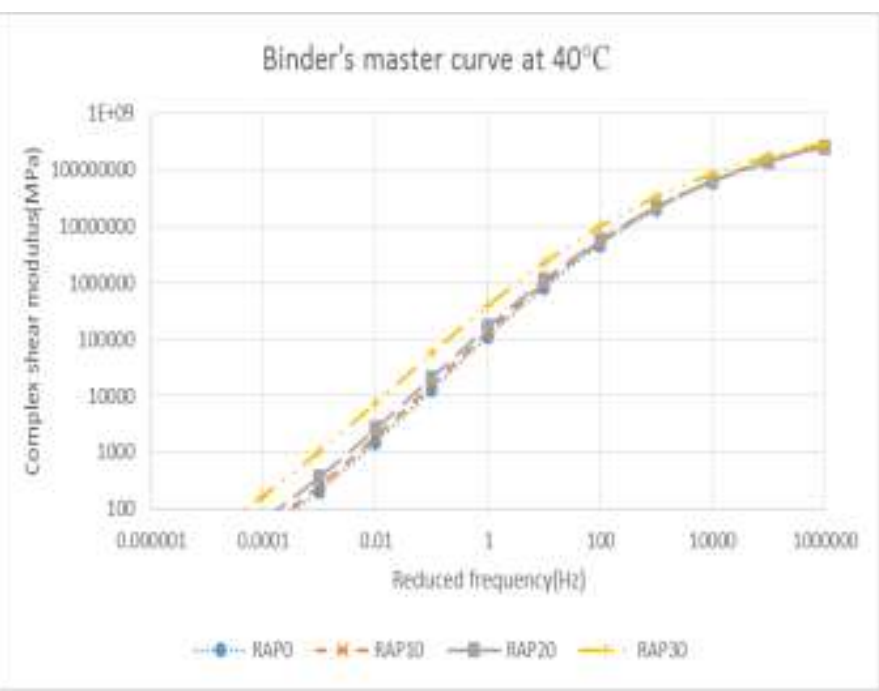

Figure 5. Master curve of binders recovered from mixtures at $4^{\circ} \mathrm{C}$ reference temperature

\section{The method of modification}

To improve the accuracy of the Al-khateeb model to estimate the dynamic modulus of the mixtures in this study, some parameters of this model were adjusted. To do so, the adjustable parameters in the model were defined as (6).

$$
\left|E^{*}\right|_{m}=3\left(\frac{100-V M A}{100}\right)\left(\frac{\left(a+b \frac{\left|G^{*}\right|_{b}}{V M A}\right)^{g}}{d+\left(e \frac{\left|G^{*}\right|_{b}}{V M A}\right)^{f}}\right)\left|G^{*}\right|_{g}
$$

where, a,b,c,d,e and $\mathrm{f}$ are the optimisation parameters and the rest of the parameters are as the same as defined previously. Moreover, the summation of square error (SSE) 
Proc. of the Fourth International Conference on Advances in Civil, Structural and Environmental Engineering - ACSEE 2016. Copyright $(\odot$ Institute of Research Engineers and Doctors. All rights reserved.

ISBN: 978-1-63248-114-6 doi: 10.15224/ 978-1-63248-114-6-30

function, was defined as an objective function to determine the accuracy of each set of parameters as shown in (7).

$$
\text { Objective function }=\sum_{i=1}^{n} \frac{\left(V_{m_{\mathrm{i}}}-V_{p_{\mathrm{i}}}\right)^{2}}{\left(V_{m_{\mathrm{i}}}\right)^{2}}
$$

where, $\mathrm{n}$ is the number of data points, $\mathrm{V}_{\mathrm{m}}$ is the $\mathrm{i}_{\text {th }}$ measured value and $V_{p}$ is the $i_{\text {th }}$ predicted value by modified Al-khateeb model. To find the optimum set of optimization parameters, the Solver tool in Microsoft Excel was used to minimize the value of the objective function in (7) and using the data available in this study.

\section{Results and discussions}

In this section, the results of the original Al-khateeb model are evaluated using the 150 data points available in this study and then in the next subsection it will be modified to achieve better accuracy. To compare the results of a prediction model and measured from the experiment, a parameter as (8) shows is defined which shows the error between the measured and predicted value in percentage form.

$$
\text { Error }(\%)=\frac{\text { Measured Value }- \text { Predicted Value }}{\text { Measured Value }} \times 100
$$

\section{A. Evaluation}

In Fig. 6 the outcome of original Al-khateeb model and the actual values of dynamic modulus are compared.

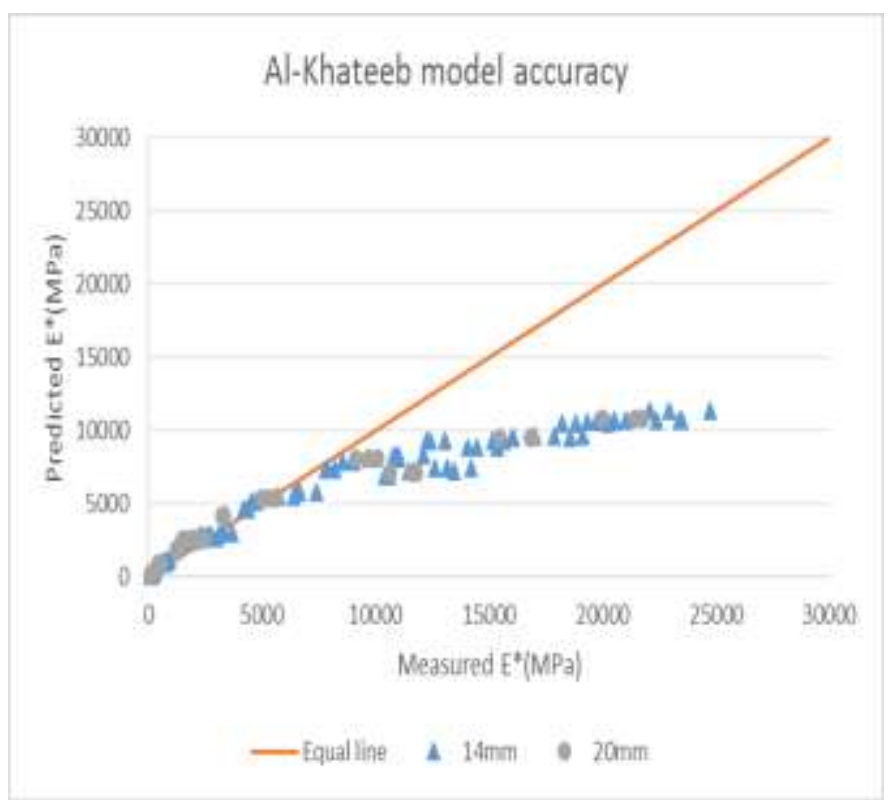

Figure 6. The accuracy of Al-khateeb model to predict $\mathrm{E}^{*}$ of 14 and $20 \mathrm{~mm}$ mixtures

It is obvious that for stiffer samples, $E^{*}$ higher than $4000 \mathrm{MPa}$, the model underestimated the results while in softer samples, $E^{*}$ lower than 4000 , it overestimated the actual results. It is also indicated that the nominal size of the aggregates had no meaningful effect on this trend.

The error or this model is plotted in Fig. 7. This fig shows that for samples which showed a low dynamic modulus (low loading frequency or high temperature or both) the overestimation error might reach to $-130 \%$ while in higher values of $\mathrm{E}^{*}$ (high frequencies, low temperatures or both) the error has an increasing trend with $\mathrm{E}^{*}$ and it can reach to $60 \%$ (underestimation).

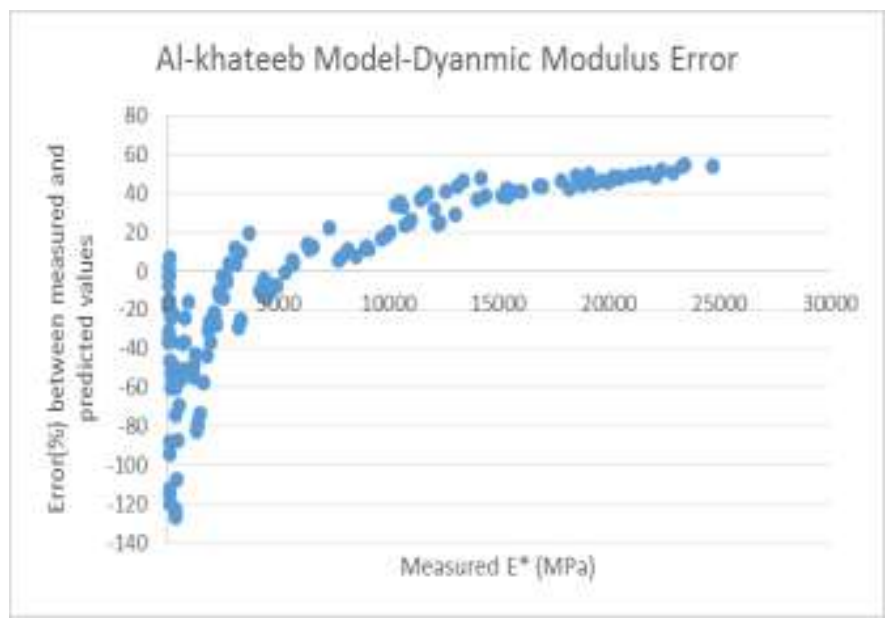

Figure 7. The error of Al-khateeb model versus measured $\mathrm{E}^{*}$

In other words, the original Al-khateeb model did not estimate the dynamic modulus of the samples in this study satisfactorily.

\section{B. Modification}

As the original Al-khateeb model did not perform well in the research, the model was modified. Table II shows the result of optimization process on adjustable parameters and (9) illustrates the modified model based on data in this study.

TABLE II. OPTIMIZATION PARAMETERS OF ORIGINAL AND MODIFIED AL-KHATEEB MODEL

\begin{tabular}{|c|c|c|c|c|c|c|}
\hline & \multicolumn{5}{|c|}{ Optimisation Parameters } \\
\hline Model & $\mathrm{a}$ & $\mathrm{b}$ & $\mathrm{c}$ & $\mathrm{d}$ & $\mathrm{e}$ & $\mathrm{f}$ \\
\hline $\begin{array}{c}\text { Original } \\
\text { model }\end{array}$ & 90 & 10000 & 0.66 & 1100 & 900 & 0.66 \\
\hline $\begin{array}{c}\text { Modified } \\
\text { model }\end{array}$ & 205.7 & 3548 & 0.753153 & 2209 & 253.3 & 0.719247 \\
\hline
\end{tabular}

$$
\left|E^{*}\right|_{m}=3\left(\frac{100-V M A}{100}\right)\left(\frac{\left(205.7+3548 \frac{\left|G^{*}\right|_{b}}{V M A}\right.}{2209+\left(253.3 \frac{\left|G^{*}\right|_{b}}{V M A}\right)^{0.75153}}\right)\left|G^{*}\right|_{g}
$$


Proc. of the Fourth International Conference on Advances in Civil, Structural and Environmental Engineering - ACSEE 2016. Copyright $(\odot$ Institute of Research Engineers and Doctors. All rights reserved.

ISBN: 978-1-63248-114-6 doi: 10.15224/ 978-1-63248-114-6-30

The performance of the modified model is far better than the original model as it can be seen in Fig. 8. In the whole range of $\mathrm{E}^{*}$, the modified model shows a balanced performance and does not tend to underestimate or overestimate the values in certain areas.

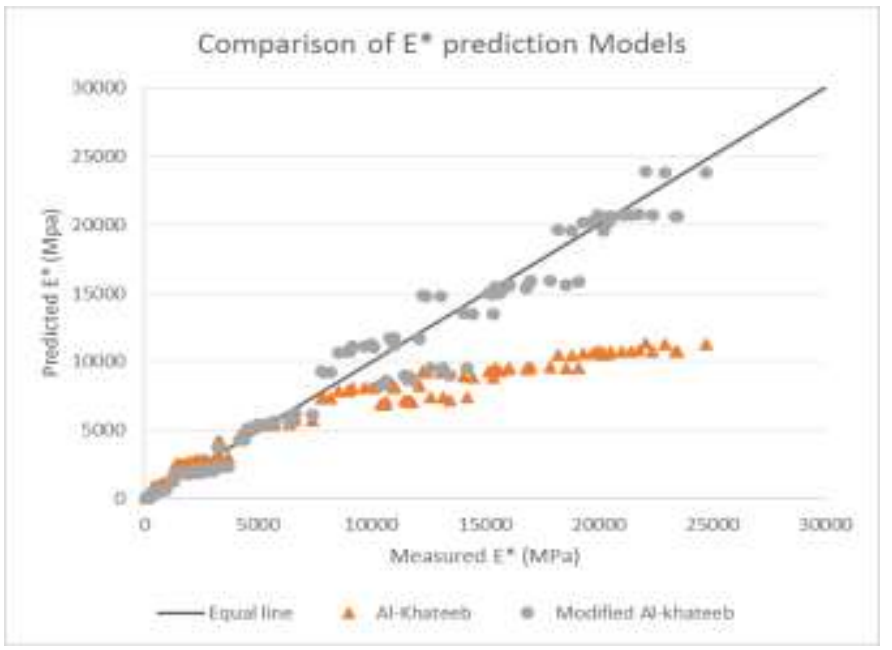

Figure 8. Comparison the accuracy of modified and original Al-khateeb model

Also, as Fig. 9 shows, the level of error has dropped significantly. For lower $\mathrm{E}^{*}$ values (less than $15000 \mathrm{MPa}$ ), the maximum error is about $40 \%$ while for samples with higher $\mathrm{E}^{*}$ (greater than $15000 \mathrm{MPa}$ ), the maximum error is less than $20 \%$.

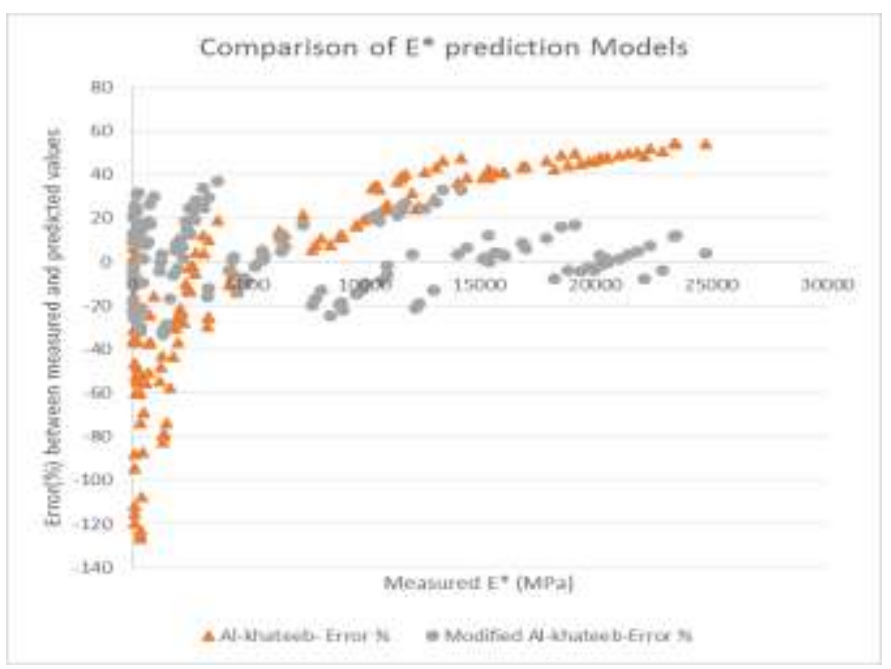

Figure 9. Comparison of the error of original and modified Al-khateeb model

\section{v. Conclusion}

This research illustrated that the original Al-khateeb model was not able to accurately estimate the dynamic modulus of the samples made using WA's materials and specifications. The model underestimates the samples with higher dynamic modulus while overestimating the dynamic modulus of samples with lower dynamic modulus. Also, the error levels of

this model can be very high and even reach to $-130 \%$ (overestimation) at lower $\mathrm{E}^{*}$ to $60 \%$ (underestimation) at higher $\mathrm{E}^{*}$. To correct this weak performance, the parameters of this model were modified to match the 150 point data set available in this study. The modified model performed well in predicting the dynamic modulus of the samples with no tendency to underestimate or overestimate the result in certain levels of $E^{*}$ while it showed significantly lower levels of error which is less than 40 and 20\% for samples with low and high values of $\mathrm{E}^{*}$ respectively.

\section{Acknowledgment}

The author would like to sincerely acknowledge the Western Australia Main Roads, which has supported this project by facilitating the required material and funding for this project through the Western Australia Pavement Asset Research Centre (WAPARC). The author also wishes to thank Darren Isaac, Pavement Technical Officer at Curtin University's Geomechanics laboratory, whose participation was really appreciated in carrying out laboratory experiments and technical support.

\section{References}

[1]
AASHTO, Mechanistic-Empirical Pavement Design Guide - A Manual of Practice (Interim Edition). 2008.

LI, Q., et al., Mechanistic-empirical pavement design guide (MEPDG): a bird's-eye view. Journal of Modern Transportation, 2011. 19.

Sondag, M.S., B.A. Chadbourn, and A. Drescher, Investigation Of Recycled Asphalt Pavement (RAP) Mixtures. 2002, Department of Civil Engineering, University of Minnesota.

Lee, H.S., S. Kim, and B. Choubane, Construction Of Dynamic Modulus Master Curves Using Resilient Modulus and Creep Test Data. 2011, State of Florida ,Department of Transportation

AASHTO, Determining Dynamic Modulus of Hot Mix Asphalt, in TP 62-07. 2007.

Bonaquist, R., Report 614 Refining the Simple Performance Tester for Use in Routine Practice NCHRP 9-29. 2008, NCHRP.

Timm, D.H. and M.M. Robbins, Evaluation of Dynamic Modulus Predictive Equations for Southeastern United States Asphalt Mixtures. Transportation Research Record: Journal of the Transportation Research Board, 2011. 2210(-1): p. 122-129.

Al-Khateeb, G., et al., A New Simplistic Model for Dynamic Modulus Predictions of Asphalt Paving Mixtures. AAPT, 2006. 75E.

Kim, Y.R., et al., LTPP Computed Parameter: Dynamic Modulus. 2011, Ferederal Highway Administration (FHWA),

Yousefdoost, S., et al., Evaluation of Dynamic Modulus Predictive Models for Typical Australian Asphalt Mixes, in 15th APAA International Flexible Pavement Conference. 2013: Brisbane, Australia.

Main Roads Western Australia, Bulk Density And Void Content Of Asphalt, in 733.1.2012.

Clyne, T.R., et al., Dynamic And Resilient Modulus Of Mn/Dot Asphalt Mixtures. 2003, University of Minnesota.

Main Roads Western Australia, Bitumen Content And Particle Size Distribution Of Asphalt And Stabilised Soil: Centrifuge Method, in WA 730.1.2011.

NSAI, EN12697-3-2013-Bituminous mixtures - Test methods for hot mix asphalt - Part 3: Bitumen recovery: Rotary evaporator. 2013.

Denneman, E., AP-T248-13 Improved Design Procedures for Asphalt Pavements: Pavement Temperature and Load Frequency Estimation. 2013, Australian Road Research Board (ARRB),. 